\title{
Perspectives of WIC Staff Regarding Physical Activity Levels and Behaviors of Latino Preschool Children
}

\author{
Ana Cristina Lindsay ${ }^{1, *}$, Mary Greaney ${ }^{2}$, Judith A. Salkeld ${ }^{3}$ and Jennifer Walsh ${ }^{4}$ \\ ${ }^{1}$ Exercise and Health Sciences Department, College of Nursing and Health Sciences, University of \\ Massachusetts Boston, Boston, MA, USA \\ ${ }^{2}$ Department of Kinesiology, College of Human Sciences and Services, University of Rhode Island, Kingston, \\ RI, USA \\ ${ }^{3}$ Department of Nutrition, Harvard School of Public Health, Boston, MA, USA \\ ${ }^{4}$ Florida Family Nutrition Program, University of Florida, Gainesville, FL, USA
}

\begin{abstract}
Background: Racial and ethnic disparities in physical activity (PA) are evident, with non-Hispanic Black and Mexican American children engaging in less vigorous activity than non-Hispanic White children. Collaborating with public health programs serving at-risk populations, such as the WIC program may be an effective way to promote the development of healthful PA behaviors among low-income preschool children and families. This paper explores WIC staff perceptions, attitudes, barriers, and facilitators related to PA levels and behaviors among low-income Latino preschool children and families, as well as the role the WIC program may play in promoting PA among low-income populations.
\end{abstract}

Methods: A qualitative study was conducted with a sample of WIC staff in the State of Rhode Island (RI), Northeast United States. Individual, semi-structured interviews were carried out with 21 WIC staff working directly with Latino clients enrolled in the WIC program. Thematic content analysis was used.

Results: The majority of WIC staff reported their Latino clients facing many barriers that limit their ability to be physically active, including busy and multiple shift schedules, lack of access to safe outdoor spaces, financial constraints to attending programs and recreational facilities, lack of transportation getting to safe outdoor spaces and facilities, etc. WIC staff identified several ways that the WIC program could increase the promotion PA among Latino families including partnering with local organizations such as the YMCA, Boys and Girls Club to provide increased access and opportunities for PA among low-income, Latino families.

Conclusions: Study findings add to the existing literature suggesting that the WIC program is an important venue for educating low-income, Latino children and families about the importance of establishing early healthy PA habits within the context of overall health and development. Findings also highlight the need for a continuing effort to integrate the promotion of PA as part of the WIC program. In addition, findings highlight WIC staff desire for additional training and resources in promotion of PA.

Keywords: Physical activity, sedentary behaviors, Latino, children, WIC program.

\section{BACKGROUND}

Adequate physical activity (PA) positively influences the immediate and long-term health of children; with physically active children having healthier cardiovascular profiles, leaner body frames, and developing higher peak bone mass compared to physically inactive children. Furthermore, children who are physically active early in life have a reduced risk for large adiposity gains in elementary school through adolescence [1-5]. PA is also a key component of energy balance and promoting physical activity is an essential component in the prevention of childhood obesity [1, 6-8]. A growing body of research studies suggests that patterns of decreased physical activity

${ }^{*}$ Address correspondence to this author at the Exercise and Health Sciences Department, College of Nursing and Health Sciences, University of Massachusetts Boston, Boston, MA, USA; Tel: 617-287-7579; Fax: 617-2877527; E-mail: Ana.Lindsay@umb.edu and increased sedentary behaviors are associated with increased risk of overweight and obesity in preschool children [9-11].

PA guidelines for young children in the U.S. have been set by the National Association for Sport and Physical Education (NASPE), which recommends that preschool-aged children accumulate at least 120 minutes of physical activity per day, with 60 minutes coming from structured physical activity, and 60 minutes from unstructured or spontaneous active play [12]. In addition, the NASPE guidelines state that preschoolers should not be sedentary for more than 60 minutes at a time, except when sleeping [12].

Despite well-documented positive effects of PA on children's health, research shows that physical activity levels of children have declined in the past decades due to changes in the social and physical environment and racial/ethnic disparities are evident $[13,14]$. 
Patterns of PA vary significantly in different racial/ethnic groups. A recent study examining differentials in the prevalence of 23 parent-reported health, chronic condition, and behavioral indicators including physical activity and sedentary behaviors among 91,532 children of immigrant and U.S.-born parents found that compared with native-born nonHispanic White children, the adjusted odds of physical inactivity were $154 \%$ higher for immigrant Hispanic children [15]. In addition, the study also showed that an estimated $60.9 \%$ of immigrant Hispanic children did not participate in sports compared with $33.4 \%$ of immigrant non-Hispanic Black children, and $31.7 \%$ of immigrant non-Hispanic White children [15]. Another recent study showed that Hispanic preschool children spent a total of 43.9 minutes of their day engaged in moderate-tovigorous $\mathrm{PA}$, which is less than the recommended $\mathrm{PA}$ guidelines of at least 60 minutes of moderate-intensity PA each day for this age group [14]. Furthermore, this study found that children mean percentage time spent in sedentary behaviors was $69.8 \%$ (SD: 18.5).

Latino children represent the largest and most rapidly growing minority population group in the United States, and childhood obesity is a major public health concern among Latino youths living in the U.S. [6, 7, 16-18].

Collaborating with public health programs serving at-risk populations, such as the Supplemental Nutrition Program for Women, Infants and Children (WIC) may be an effective way to promote healthful PA behaviors among low-income, Latino families [5, 19-21]. WIC has traditionally focused on improving nutritional status of low-income pregnant and post-partum women and their children up to age five and providing nutrition education. However, since 2000 , the organization has broadened its mission to incorporate strategies for promoting PA among their clients. To date only a few interventions to increase PA and/or reduce sedentary behaviors among preschool-aged children have been implemented in WIC settings [5]. Fit WIC, a childhood obesity prevention program, implemented in five states, supports the WIC program as a venue for promoting $\mathrm{PA}$ and developing community collaborations to promote PA among low- income families [5]. Nevertheless, limited research has been conducted to examine the perspectives of WIC staff regarding the broadening of the WIC program focus to include the promotion of PA. Shedding light on WIC staff perceptions, attitudes, barriers and facilitators related to PA levels and behaviors of minority children and families, including Latinos should facilitate the development of strategies to assist an increased focus WIC program's focus on the promotion of PA.

Therefore, the present qualitative study was designed to explore WIC staff: 1) perceptions, attitudes, barriers and facilitators related to PA levels and behaviors of Latino children and families; 2) views and suggestions on how the WIC program can help promote increased PA among low-income Latino preschool-aged children and families; and 3) selfefficacy related to counseling and training on the promotion of PA among low-income families.

\section{METHODS}

\section{Design \& Sample}

The Latino Preschool PA (LPPA) study utilized a mixed methods research design including qualitative (i.e., individual interviews and focus groups) and quantitative (i.e., self-reported and objective assessment of PA) to examine how the social-cultural context of low-income, Latino families influences PA and sedentary behaviors of Latino preschool-aged children, and to identify barriers and facilitators to promoting PA among this population. The LPPA study used themes adapted from socio-ecological and social contextual models to examine the role of social and cultural pathways on PA and sedentary behaviors of low-income, Latino preschool-aged children and their families [22-24]. Furthermore, the LPPA was designed to explore ways in which the WIC program could become an important venue to promote PA among lowincome, Latino families.

\section{Sample and Recruitment}

Five cities in Rhode Island (RI) with large Latino populations were purposively sampled to include WIC clinics serving the largest percentage of Latino families in that state. With the help of the RI Department of Health-WIC Program we identified and purposively selected WIC clinics serving predominantly Latino populations. The WIC clinic director of selected WIC clinics provided contact details and help recruit WIC staff working directly with Latino families. Eligibility criteria included being employed as a nutritionist or nutrition assistant, working directly with WIC clients, and being employed at the participating sites for at least 12 months. Each clinic director provided names of all eligible WIC staff and sent them an invitation letter developed for the study. A total of 24 WIC staff were identified as eligible to participate in the study. Following identification of all eligible participants, a 
research team member (JS) tried to recruit all eligible participants by contacting (at least 3 attempts were made) and arranging interview sessions at a convenient time dependent on WIC staff workload.

\section{Data Collection}

Prior to the conducted of interviews written signed informed consent was obtained for every WIC staff. All interviews were conducted in WIC clinics during the Fall (October - December) of 2011 by research staff trained in qualitative research methods using a semistructured interview guide developed for the study. All interviews were conducted in English and lasted approximately 45 minutes. All interviews were audiorecorded after obtaining oral consent from participants. Participants received a \$20 US gift card to thank them for their time. Institutional Review Boards at the Harvard School of Public Health and the Rhode Island Department of Health approved the study.

A semi-structured interview guide was developed and pretested in two pilot interviews with WIC staff from a WIC clinic not participating in the study by the research team for the study. Interview topic guide included WIC staff: 1) knowledge, attitudes and beliefs related to PA; 2) Perceptions and attitudes related to PA levels and behaviors of Latino preschool children and their families; 3) Perceptions, attitudes, and practices related to their role and overall WIC program role in the promotion of PA; 4) Reflections on selfefficacy related to counseling on PA promotion; 5) Training issues and resources for counseling on issues related to PA; 6) Suggestions for ways in which WIC can play an increased role in promotion of PA among low-income populations served by the WIC program.

\section{Data Analysis}

An independent consultant transcribed all recordings with identifiers removed. Using a thematic analysis approach, two research members (ACL and MG) trained in qualitative methods manually and systematically coded and analyzed interview data to identify salient and convergent themes. Standard methods in qualitative data analysis were followed, including verbatim transcription of audiotaped interviews [25]. The analysis plan also included an initial review of all transcripts from interviews in order to develop an initial codebook. All transcripts were manually coded to create an index; coding inconsistencies were discussed and resolved, then reviewed for developing a list of possible emergent themes [25]. In a second phase of the data analysis, sub-themes within each theme were identified through immersion and multiple re-readings of the transcripts. Each theme and sub-theme was assigned a numeric code, which reviewers independently summarized. Coded responses were organized into a schematic document to assess the relative emphasis given to each theme and sub-themes across interviews. Descriptive analyses were calculated from sociodemographic questionnaires using Microsoft Excel 2008.

\section{RESULTS}

Twenty-one WIC staff were recruited (21 out of 24 eligible; $87.5 \%$ ) to participate in individual, in-depth interviews. This sample included thirteen WIC nutritionists (six of whom were WIC program directors) and eight WIC nutrition assistants. Nineteen participants were female $(n=19 ; 90.5 \%)$, and only two were male $(9.5 \%)$ eight were Hispanic $(38 \%)$ and twelve $(57 \%)$ had been in their current position more than five years. The percentage of Latinos served by the clinics ranged from percent 55 - 70 per cent.

\section{Themes from Interviews}

We identified 13 themes in our analysis and grouped them into three major categories that characterized WIC staff perspectives on PA levels and behaviors among Latino preschool children and families and role of WIC program in promotion of PA. The three categories included: (1) WIC staff perceptions, beliefs and attitudes related to PA of Latino families, (2) WIC staff perception of the role of the WIC program in promoting increased PA among Latino children and families; (3) WIC staff general perception of self-efficacy related to PA counseling and desire for additional training and resources in PA counseling. Emergent themes and sub-themes with supporting quotes are summarized below by category (see Tables 1-3).

\section{WIC Staff Perceptions, Beliefs and Attitudes Related to PA in General and PA Levels and Behaviors of Latino Families}

All participants perceived PA as being important to overall health and associated with obesity (Theme 1). The majority of interviewees were aware of daily minimum PA recommendations for children. Most commented on the importance of developing healthful PA habits when young; several noted that developing a healthy life style early in life including PA sets a solid foundation for life (Theme 2). 
Table 1: IC Staff' Perspectives on Physical Activity Levels and Behaviors of Latino Families They Work With

\begin{tabular}{|c|c|}
\hline Themes & Representative Comments from Interview Participants \\
\hline $\begin{array}{l}\text { 1. Physical Activity is Key to Overall } \\
\text { Health }\end{array}$ & $\begin{array}{l}\text { "Physical activity is a key component of achieving overall good health" } \\
\text { "Most Latino parents I work with don't perceive that physical activity is as important for their children } \\
\text { overall health, and for the ones who do, it's just not a priority ... They have too many other things like } \\
\text { paying the bills, to think about ..." }\end{array}$ \\
\hline $\begin{array}{l}\text { 2. A Healthy Lifestyle Should be } \\
\text { Established Early in Life }\end{array}$ & $\begin{array}{l}\text { "Setting a foundation early in life for healthy habits is very important ... with nutrition and healthy eating } \\
\text { we need to teach children to be active very early on..." }\end{array}$ \\
\hline $\begin{array}{l}\text { 3. Physical Activity is Not a Priority } \\
\text { for Latino Families Latino Families }\end{array}$ & $\begin{array}{l}\text { "I think they [Latino parents] do understand the importance of physical activity. I don't think it's thought } \\
\text { of as much as a priority as nutrition and eating the right foods..." } \\
\text { "I think they [Latino parents] think it is important but it might not be the number one thing in their } \\
\text { minds. They have so many other things on their minds that they don't necessarily have the time to } \\
\text { focus on that because they're focusing on making money or getting the assistance they need or } \\
\text { moving or they're getting evicted..." }\end{array}$ \\
\hline $\begin{array}{l}\text { 4. Latino Families Lead a } \\
\text { Sedentary Lifestyle }\end{array}$ & $\begin{array}{l}\text { "...Watching TV is a big part of the family life ... the kids have their own TV and a lot of parents } \\
\text { underestimate how much TV their kid watches ..." } \\
\text { "If they [mothers] are busy doing their chores they set up the TV for the kids to keep themselves } \\
\text { entertained while they are doing their chores around the house. They think that's not bad because } \\
\text { their kids are watching something good on TV and at the same time learning English. So, they justify } \\
\text { watching a lot of TV as a good thing for their children." }\end{array}$ \\
\hline $\begin{array}{l}\text { 5. Latino Parents Misperceive Their } \\
\text { Children's Physical Activity Levels }\end{array}$ & $\begin{array}{l}\text { "Their attitude is that, 'oh they're moving around all the time. They just think they are getting tons of } \\
\text { exercise. Where they might actually be getting some if they are moving around a lot, but they are not } \\
\text { always getting as much as they think they are. The mothers' perceptions are that their children are } \\
\text { getting enough physical activity but they are really not." }\end{array}$ \\
\hline $\begin{array}{l}\text { 6. Adults are Role Models for } \\
\text { Physical Activity for their Children }\end{array}$ & $\begin{array}{l}\text { "Children depend on the level of and physical activity habits of others in the house. If an adult is sitting } \\
\text { down, then the kid is going to take that habit. Whereas, if it's a household where the parents are } \\
\text { active, I'm pretty sure the kids will be active" } \\
\text { "It is very important especially nowadays with the rising rates of obesity to make sure that kids are } \\
\text { active ... and if parents are active, kids will be too..." }\end{array}$ \\
\hline $\begin{array}{l}\text { 7. Latino Families enrolled in WIC } \\
\text { Face Many Barriers to Being } \\
\text { Physically Active }\end{array}$ & $\begin{array}{l}\text { "In the neighborhoods they live in, the parents don't always feel safe letting their children go outside } \\
\text { and play...they have a lot of kids to take care of, or they have their own needs, or they are stressed } \\
\text { out, so they don't always get out and find a safe area for their kids to play." } \\
\text { "...Latino families like other low-income families face many barriers that prevent them from being } \\
\text { physically active. The neighborhood where they live is usually not safe, housing does not allow for } \\
\text { kids to be moving around in a backyard, the parks are not in great condition... it is really not easy to } \\
\text { go out and just be active." }\end{array}$ \\
\hline
\end{tabular}

Table 2: The Role of the WIC Program in Promoting Increased Physical Activity among Latino Children and Families

\begin{tabular}{|l|l|}
\hline Themes & Representative Comments from Interview Participants \\
\hline \hline $\begin{array}{l}\text { 8. WIC has Traditionally Focused on } \\
\text { Nutrition Counseling }\end{array}$ & $\begin{array}{l}\text { "We have to do the nutrition assessment. We've to talk about whatever the need is, in terms of } \\
\text { the nutrition assessment. But then we have very little time to talk about physical activity." } \\
\text { "We talk about obesity, but it is most nutrition related with like blurbs related to physical activity. } \\
\text { Now they are trying to switch over to a more value-enhanced nutrition system, so talking about } \\
\text { what the parents want to talk about. But I do think we need more training..." }\end{array}$ \\
\hline $\begin{array}{l}\text { 9. WIC Staff Counseling is Primarily } \\
\text { Becused on Reducing Sedentary } \\
\text { Necessarily Promoting Physical Activity }\end{array}$ & $\begin{array}{l}\text { "Most of what we do is to ask how many hours of TV each child over the age of } 2 \text { watches. We } \\
\text { always ask about how much TV a child watches and we explain to the mother that the } \\
\text { recommendation is that children watch less than } 2 \text { hours of TV a day ..." }\end{array}$ \\
\hline $\begin{array}{l}\text { 10. WIC Needs to Further Increase } \\
\text { Awareness about the Importance of } \\
\text { Physical Activity }\end{array}$ & $\begin{array}{l}\text { "We need to do more in terms of increasing parents' awareness of the importance of physical } \\
\text { activity." } \\
\text { "Parents need information on simple ways in which they can keep their kids physically active such } \\
\text { as playing jump rope, indoor hopscotch, etc." }\end{array}$ \\
\hline $\begin{array}{l}\text { 11. Increasing Families' Access to } \\
\text { Recreational Facilities and Programs is } \\
\text { Essential to Promoting Increased } \\
\text { Physical Activity among Latino Families }\end{array}$ & $\begin{array}{l}\text { "They need access to the parks. They need access to community centers where they can } \\
\text { exercise. They don't have lots of opportunities here or they don't know where to go, so we've } \\
\text { been providing them with some information regarding that. They don't have a lot of money to join } \\
\text { organizations so sometimes the YMCA has financial aid where they pay according the income of } \\
\text { the family." }\end{array}$ \\
\hline
\end{tabular}


(Table 2). Continued.

12. The WIC Program Can Play a Role in Helping Latino Families Overcome Barriers to Being Physically Active
"I think if we were able to focus on the indoor activities if we had playgroups, family exercise classes, videos... provide them with the means to accomplish what we are asking them to do...something that is convenient."

"If there are more programs to get them involved [in pa], they'd be more apt to do it, instead of just telling or explaining ... like you can take them out for a walk or out on a bike or even playing games inside the house that include it. I think they need a little extra push where there are other people doing it with them and they are involved. In the past, we had free exercise classes called "Family Exercise Class" and they were really popular."

Table 3: WIC Staff Desires Additional Training on Counseling Related to Physical Activity

\begin{tabular}{|l|l|}
\hline Themes & Representative Comments from Interview Participants \\
\hline \hline $\begin{array}{l}\text { 13. WIC Staff Lack Self-Efficacy in } \\
\text { Counseling Clients on Physical Activity } \\
\text { and Desire More Training }\end{array}$ & $\begin{array}{l}\text { "I think it would be nice to have more information about what is appropriate for kids at different } \\
\text { ages and what they should be doing. Because I don't really know if I feel confident in what I } \\
\text { should be recommending for this preschool-age children... If we were offered the training, we } \\
\text { would have the ability to talk about physical activity at an appointment. But we don't have the } \\
\text { complete expertise, like we do with nutrition. So we need that training." } \\
\text { "I think also learning about the different aspects of the different Hispanic cultures. Like I know } \\
\text { for instance, how important it is in Guatemala, dancing is a part of the lifestyle. So that's why I } \\
\text { bring out dancing. So, learning more about the different populations and cultures would be } \\
\text { helpful. What do they do in their country for exercise? What do they do? Do they run? Do they } \\
\text { dance? And then bring that into counseling and education." } \\
\text { "The reality is that most of the focus of our WIC counseling and training is around nutrition ... } \\
\text { we need to dedicate more time to physical activity, but we also need more training because } \\
\text { that's not a big part of our training so it is easier to focus on what you feel more comfortable } \\
\text { with ..." }\end{array}$ \\
\hline
\end{tabular}

The majority of WIC staff reported that most Latino clients believe that PA is important for overall health, but that PA is not a priority for most Latino families due to barriers such as competing priorities such as providing financially for their families including securing housing, food, and medical care needs (Theme 3 ). Most WIC staff discussed their Latino clients leading very sedentary lifestyles (Theme 4) and cited excessive time spent watching TV and playing video games. Furthermore, some WIC staff noted Latino clients' perception of the TV as a "good babysitter" due to beliefs that educational programs may facilitate English language learning of their children (Theme 4).

Several WIC staff also reported that many Latino mothers often overestimate their children's PA and perceive their children as being sufficiently physically active (Theme 5) and thus do not believe they need advice from WIC staff on their children PA levels and behaviors. The majority of staff spoke of parental behavior as an important influence on their children's PA levels and behaviors (Theme 6), with young children modeling behaviors, healthy and unhealthy, of their parents and other adults living in the household. Staff reported perceptions of Latino parents being very sedentary themselves and having sedentary behaviors such as excessive TV-watching.
Nearly all WIC staff reported that the Latino families they work with face many barriers to being physically active, including lack of time, fatigue and stress, safety concerns, cold weather, lack of available and accessible recreational facilities in good conditions, financial constraints, and lack of transportation (Theme 7). Many WIC staff felt that increased access to affordable PA programs and safe parks/recreational spaces that are in good condition would promote increased PA among Latino families and children (Theme 7).

\section{WIC Program Role in Promoting Increased PA among Latino Children and Families}

Interviewees stressed the need for WIC to continue educating parents about the importance of PA and address misperceptions of Latino parents about their children's PA levels (Theme 10). They stated this could be done by giving families skills and strategies to increase their children's PA (Theme 11) that also recognize the social, cultural and financial context of Latino families plus facilitating increased opportunities for PA (Theme 12). Almost all believed that WIC should provide clients with lists of community resources and recreational opportunities for PA. Interviewees spoke of wanting educational handouts on ways that families can be physically active and family-friendly exercise videos/DVDs to share with clients (Theme 12), These 
materials would need to be culturally and linguistically appropriate (e.g., appropriate literacy levels, Spanish and English materials) for the population they serve.

When probed on ways to help clients overcome barriers, most interviewees suggested that WIC provide vouchers or discounted memberships to community facilities and programs. Additionally WIC could provide incentives such as free passes to community events promoting recreational PA for children and their families (Theme 12). A few suggested that a form of indoor PA could be incorporated into WIC appointments. Barring clinic space limitations, this could provide an opportunity to demonstrate some simple methods of incorporating indoor PA into family life. Furthermore, some believe that Latino clients would benefit from counseling on convenient ways to incorporate PA into daily life (e.g., using stairs).

\section{Barriers to WIC in Promoting Increased PA among Latino Children and Families}

Although most WIC staff reported assessing clients' sedentary behaviors (i.e., screen time) and discussing the importance of PA as part of WIC visits, they noted that nutrition counseling is the primary focus of their work and of their professional training (Theme 8). Consistently, they indicated that most counseling related to PA centered around educating parents and their children on the importance of setting limits on TVviewing and not necessarily on promoting physical activity (Theme 9). In addition, interviewees noted that WIC's traditional role with a heavy focus on nutrition might also be an influence on their clients' perception of PA being less important than nutrition.

\section{WIC Staff General Perception of Self-Efficacy Related to PA Counseling and Desire for Additional Training and Resources}

About half of the WIC staff reported not feeling confident or comfortable discussing PA with their clients due to their lack of training and experience in this area. Nearly all WIC staff reported that they would welcome and benefit from increased culturally specific training addressing issues relevant to promoting PA among minority populations such as Latinos (Theme 13).

\section{DISCUSSION}

This study adds to the literature of research exploring the perceptions, beliefs and attitudes of WIC staff about PA levels and behaviors of Latino preschool-aged children and families, as well as their perspectives about the role of the WIC program in promoting PA among this population. Such work is critical to guide the development of effective educational programs to promote PA among lowincome Latino preschool-aged children and their families, a minority group with one of the highest childhood obesity rates $[6,16,17]$.

Overall, WIC staff reported that based on their experience, most Latino families lead sedentary lives due to competing life demands, environmental and socio-cultural barriers. This finding is consistent with current research literature showing that Latino adults and children have more sedentary lifestyles than nonHispanic whites and that prevalence of inadequate PA is higher among Latinos than in other racial groups [6]. Sedentary lifestyles of Latino parents is of great concern due to a well-documented association between the PA levels of parents and that of their children. This find highlights a need to increase awareness among Latino parents about their role in shaping their children's development of early healthful lifestyle behaviors $[16,17]$. Many previous studies have suggested that a family-centered approach is more likely to be effective than interventions that do not target the family as a unit of change [1, 14, 23, 26, 27]. Understanding the socio-cultural and environmental influences on PA behaviors of Latino children and families is critical to developing programs and policies to prevent obesity.

WIC staff recognized the importance of PA as a key component of obesity prevention and were very receptive to enhancing their counseling on the promotion of PA. Similarly, a recent study by Davison et al. documented WIC staff awareness of the importance of and receptiveness to increase the promotion of PA in the WIC setting [28].

WIC staff reported that their Latino clients face many barriers that limit their ability to being physically active, including busy and multiple shift schedules, lack of access to safe outdoor spaces, financial constraints to attending programs and recreational facilities, lack of transportation getting to safe outdoor spaces and facilities, etc. This concurs with results from previous studies showing that neighborhood safety, competing demands and financial constraints prevent children from meeting PA recommendations and suggest that any strategy to promote increased PA among lowincome, Latino families must consider the many barriers their families face daily [1, 2, 29].

A unique finding of this study was that WIC staff perceived that Latino parents overestimate their 
children's PA levels. An increased focus on PA education in the WIC setting could help reduce the misconception parents have about their children's actual PA levels and PA requirements for young children by increasing Latino parents' awareness of recommendations for PA for energy balance and overall physical and emotional health. WIC staff also felt that most of their training focused on nutrition and therefore the focus of their counseling and education targeted nutrition and establishing children's early healthy eating habits. Several WIC staff believed that the dominating focus on nutrition might be a contributing factor to Latino families' perceptions of nutrition being more important than PA for the overall health of their children.

WIC staff identified several ways that the WIC program can promote PA among Latino families. They emphasized that WIC could increase education of parents on the importance of PA and on PA guidelines and recommendations for children. WIC staff felt that although some Latino parents may understand the importance of PA for health, they do not view it as a top priority, indicating a need for increasing awareness of the importance of PA among Latino families, which should be done taking into consideration and addressing socio-cultural and environmental barriers. For example, WIC staff participating in this study suggested that WIC could partner with local organizations such as the YMCA, Boys and Girls Club to provide increased access and opportunities for PA among low-income, Latino families.

Although WIC staff appeared to understand the importance of PA in promoting healthy weight and lifestyle and most were versed in current $P A$ recommendations for children, they spoke of needing additional training on promoting PA in a manner that is culturally relevant for their Latino clients. They also spoke of wanting access to culturally appropriate, educational materials, and information about free local events that promote PA, as these $t$ these could help their Latino clients overcome some barriers (e.g., financial concerns) to PA. This finding is in line with that of previous research indicating that there is a need for increased and continuous professional training of WIC staff to promote PA among the families with whom they work [1, 28, 30]. As interviewees noted, training would need to be culturally sensitive to help Latino families integrate PA into their daily lives.

To date only a few interventions to increase PA and/or reduce sedentary behaviors among preschool- aged children have been implemented in WIC settings $[1,28,31]$. Fit WIC, a childhood obesity prevention program, implemented in five states, supports WIC as a venue for promoting $\mathrm{PA}$ and developing community collaborations to promote PA among low income families [1, 28, 31]. Findings from our study adds to the literature by providing evidence supporting implementing interventions in the WIC setting, and WIC staff willingness to increase the focus of their counseling on the promotion of PA. Nevertheless, our study also indicates that WIC staff are likely to need additional education and training in counseling on PA to enhance their ability to effectively promote increased PA levels and early development of PA behaviors among low-income Latino children and their families.

The present study should be considered in light of its strengths and limitations. Findings are based on a small, non-random, purposive sample of WIC staff and WIC programs, which may limit applicability. However, interviewees were from three WIC programs serving Latino families from several ethnic backgrounds, indicating potential for generalizing among Latinos in other parts of the country. Additionally, this is one of the first studies to assess WIC staff' perspectives on PA levels and behaviors of Latino children and families. Future research should build upon the qualitative findings reported here, and quantitatively assess the relationship of WIC staff perceptions and opinions to objective assessment of PA of young Latino children and parents.

\section{CONCLUSIONS}

Results from this study add to the existing literature suggesting that the WIC program is an important venue for educating low-income, Latino children and families about the importance of establishing early healthy PA habits within the context of overall health and development. Results also highlight the importance of addressing the socio-cultural context of daily life of lowincome, Latino families and children when designing interventions to promote increased PA among this group. In addition, study results highlight influences on PA levels and behaviors of Latino children and families at the personal, family, organizational, and community level that are potentially modifiable through interventions [32, 33]. Findings support public health professionals working in collaboration with the WIC program to effectively promote PA with low-income Latino families by focusing intervention efforts on the different levels of influence. For example, at the intrapersonal by addressing the influence of family 
members' (e.g. parents and siblings) on PA and sedentary behaviors of preschool children's PA habits, at the organizational level by providing informational materials and resources on local programs that offer low cost/free opportunities for PA, and at the community, neighborhood level by helping low-income, Latino families identify potential places to be active and address ways in which to overcome barriers such as lack of safe outdoor spaces). Public health professionals and programs could also play an important role in training WIC staff on ways to promote increased PA of low-income families.

Furthermore, future research should focus on developing and evaluating the effectiveness of increased WIC staff training in counseling and promoting of PA and the use of family-centered strategies to increase PA among low-income, Latino families and young children in the WIC setting.

\section{COMPETING INTERESTS}

The authors declare that they have no competing interests.

\section{AUTHORS' CONTRIBUTIONS}

$A C L$ and $M G$ were involved in the initial conceptualization of the research question and interview guide. JS collected the data with overall supervision from $A C L$. $A C L$ and $M G$ coded the data with assistance from JS and JW. ACL was responsible for the data analysis, with input from MG, JS, and JW. $A C L$ took the lead in drafting the manuscript, with input from MG, JS, JW. All authors read and approved the final manuscript.

\section{AUTHORS' INFORMATION}

Dr. ACL is an Associate Professor in the Exercise and Health Sciences Department at the University of Massachusetts Boston. She has extensive experience in the conduct of mixed methods research among lowincome, Latino populations in the U.S. and Latin America. Dr. MG is an Assistant Professor in the Department of Kinesiology in the College of Human Sciences and Services at the University of Rhode Island. She has collaborated in several research projects using qualitative methodologies with $\mathrm{Dr}$. ACL and others. Ms. Salkeld holds a Masters degree in Health Communication, worked for several years with the WIC programs in Rhode Island and Massachusetts and has collaborated in previous research with Drs. $A C L$ and MG focusing on low-income, Latino populations. Dr. JW is a State Nutrition Specialist for EFNEP in Florida, where she is responsible for the design and development of curriculum materials, program planning, implementation and evaluation. She has worked in previous research studies with Dr. MG.

\section{ACKNOWLEDGEMENTS}

This study was supported by a grant from the National Cancer Institute (1 R21 CA131764-01A1), for which Dr. ACL was the Principal Investigator funded for the conduct of this research, and Dr. MG was the Coinvestigator. The authors gratefully acknowledge the staff of the WIC Program at the Rhode Island Department of Health for their support and guidance in the implementation of the field research. In addition, we are thankful for the support and contributions of all the WIC staff, which participated in this study, without whom this research could not have been conducted.

\section{REFERENCES}

[1] Crawford PB, Gosliner W, Strode P, et al. Walking the talk: Fit WIC wellness programs improve self-efficacy in pediatric obesity prevention counseling. Am J Public Health 2004; 94: 1480-5.

http://dx.doi.org/10.2105/AJPH.94.9.1480

[2] Davison KK, Jago R. Change in parent and peer support across ages 9 to 15 years and adolescent girls' physical activity. Med Sci Sports Exerc 2009; 41: 1816-25. http://dx.doi.org/10.1249/MSS.0b013e3181a278e2

[3] Eyler AA, Matson-Koffman D, Young DR, et al. Quantitative study of correlates of physical activity in women from diverse racial/ethnic groups: Women's Cardiovascular Health Network Project: summary and conclusions. Am J Prev Med 2003; 25(Suppl 1): 93-103.

http://dx.doi.org/10.1016/S0749-3797(03)00170-3

[4] Fakhouri TH, Hughes JP, Brody DJ, Kit BK, Ogden CL. Physical activity and screen-time viewing among elementary school-aged children in the United States from 2009 to 2010. JAMA Pediatr 2013; 167: 223-9. http://dx.doi.org/10.1001/2013.jamapediatrics.122

[5] Fitzgibbon ML, Stolley MR, Schiffer LA, Van Horn L, Kauferchristoffel K, Dyer A. Hip-hop to Health for Latino preschool children. Obesity 2006; 14: 1616-25. http://dx.doi.org/10.1038/oby.2006.186

[6] Brown WH, Pfeiffer KA, Mclver KL, Dowda M, Addy CL, Pate RR. Social and environmental factors associated with preschoolers' non-sedentary physical activity. Child Dev 2009; 80: 45-58.

http://dx.doi.org/10.1111/j.1467-8624.2008.01245.x

[7] Brownson RC, Boehmer TK, Luke DA. Declining rates of physical activity in the United States: what are the contributors? Annu Rev Public Health 2005; 26: 421-43. http://dx.doi.org/10.1146/annurev.publhealth.26.021304.1444 $\underline{37}$

[8] Centers for Disease Control. How much physical activity do children need? http://www.cdc.gov/physicalactivity/everyone/ guidelines/children.html. Accessed September 6, 2011.

[9] Biddle SJ, Pearson, N, Ross GM, Braithwaite R. Tracking of sedentary behaviours of young people: a systematic review. Prev Med 2010; 51: 345-51.

http://dx.doi.org/10.1016/j.ypmed.2010.07.018 
[10] Hodges EA, Smith C, Tidwell S, Berry D. Promoting physical activity in preschoolers to prevent obesity: a review of the literature. J Pediatr Nurs 2013; 28: 3-19. http://dx.doi.org/10.1016/j.pedn.2012.01.002

[11] Pratt M, Epping JN, Dietz WH. Putting physical activity into public health: a historical perspective from the CDC. Prev Med 2009; 49: 301-2.

http://dx.doi.org/10.1016/j.ypmed.2009.06.011

[12] National Association for Sport and Physical Education (NASPE), an association of the American Alliance for Health, Physical Education, Recreation and Dance, Active Start: A Statement of Physical Activity Guidelines for Children Birth to Five Years (Reston, VA: NASPE, 2002), 5-11. Visit www.aahperd.org/NASPE.

[13] Ramirez AG, Chalela P, Gallion KJ, Green LW, Ottoson J. Salud America! Developing a National Latino Childhood Obesity Research Agenda. Health Educ Behav 2011; 38: 251-60.

http://dx.doi.org/10.1177/1090198110372333

[14] Ruiz R, Gesell SB, Buchowski MS, Lambert W, Barkin SL. The relationship between Hispanic parents and their preschool-aged children's physical activity. Pediatrics 2011; 127: 888-95.

http://dx.doi.org/10.1542/peds.2010-1712

[15] Singh GK, Yu SM, Kogan MD. Health, chronic conditions, and behavioral risk disparities among U.S. immigrant children and adolescents. Public Health Rep 2013; 128: 463-79.

[16] Anderson RE, Crespo CJ, Bartlett SJ, Cheskin LJ, Pratt M. Relationship of physical activity and television watching with body weight and level of fatness among children: results from the Third National Health and Nutrition Examination Survey. JAMA 1998; 279: 938-42.

http://dx.doi.org/10.1001/jama.279.12.938

[17] Bautista L, Reinenger B, Gray JL, Barroso CS, McCormick JB. Perceived barriers to exercise in Hispanic adults by level of activity. J Phys Act Health 2011; 8: 916-25.

[18] Ennis S, Rios-Vargas M, Albert N: The Hispanic Population: 1020 Census Briefs. Issued 5/2011. Available at htpp://www.census.gov/prod/cen2010/briefs/c2010br-04.pdf. Accessed August 2014.

[19] McGarvey EL, Collie KR, Fraser G, Shufflebarger C, Lloyd B, Oliver NM. Using focus group results to inform preschool childhood obesity prevention programming. Ethn Health 2006; 11: 265-85. http://dx.doi.org/10.1080/13557850600565707

[20] Miles M, Huberman A. Qualitative Data Analysis: An Expanded Sourcebook. In: Sage Publications. $2^{\text {nd }}$ ed. Thousand Oaks, CA 1994.

[21] Moore LL, Nguyen US, Rothman KJ, Cupples LA, Ellison RC. Preschool physical activity level and change in body fatness in young children: The Framingham Children's Study. Am J Epidemiol 1995; 142: 982-8.

[22] McLeroy KR, Bibeau D, Steckler A, Glanz K. An ecological perspective on health promotion programs. Health Educ $Q$ 1998; 15: 351-77.

http://dx.doi.org/10.1177/109019818801500401
[23] Lindsay AC, Sussner KM, Greaney MI, Peterson KE. Influence of social context on eating, physical activity and sedentary behaviors of Latina mothers and their preschoolage children. Health Educ Behav 2009; 36: 81-96.

http://dx.doi.org/10.1177/1090198107308375

[24] Lindsay AC, Sussner KM, Greaney MI, Peterson KE. Latina mothers' beliefs and practices related to weight status, feeding, and the development of pediatric overweight. Public Health Nurs 2011 ; 28: 107-18.

http://dx.doi.org/10.1111/j.1525-1446.2010.00906.x

[25] Maxwell JA. Qualitative research design: an interactive approach. In: Sage Publications Applied Social Science Methods Series. Vol 41. Thousand Oaks, CA 2005; 214-253.

[26] Sallis JF, Glanz K. The role of built environments in physical activity, eating, and obesity in childhood. Fut Child 2006; 16: 89-108.

http://dx.doi.org/10.1353/foc.2006.0009

[27] Olivera N, Kellam SF, Menefee K, Lee J, Smith DW. Physical activity in Latino children: research and its implications. Journal of Applied Research on Children: Informing Policy for Children at Risk 2010; 1(1).

[28] Davison KK, Edmunds LS, Wyker BA, Young LM, Sarfoh VS, Sekhobo JP. Feasibility of increasing childhood outdoor play and decreasing television viewing through a family-based intervention in WIC, New York State, 2007-2008. Prev Chronic Dis 2011; 8: A54.

[29] Davison KK, Cutting TM, Birch LL. Parents' activity-related parenting practices predict girls' physical activity. Med Sci Sports Exerc 2003; 35: 1589-95.

[30] Klesges RC, Stein RJ, Eck LH, Isbell TR, Klesges LM. Parental influence on food selection in young children and its relationships to childhood obesity. Am J Clin Nutr 1991; 53: 859-64.

[31] Sekhobo JP, Egglefield K, Edmunds LS, Shackman G. Evidence of the adoption and implementation of a statwide childhood obesity prevention initiative in New York State WIC Program: the NY Fit WIC process evaluation. Health Educ Res 2012; 27: 281-91.

http://dx.doi.org/10.1093/her/cyr100

[32] Sorenson G, Emmons K, Hunt MK, et al. Model for incorporating social context in health behavior interventions: applications for cancer prevention for working-class, multiethnic populations. Prev Med 2003; 37: 188-97. http://dx.doi.org/10.1016/S0091-7435(03)00111-7

[33] Lindsay AC, Sussner KM, Pfeiffer EM, Greaney ML, Wang $M$, Peterson KE. Social-cultural, Organizational and Community Influences on Physical Activity and Sedentary Behaviors of Latina Mothers' and Their Preschool-Aged Children enrolled in the WIC Program: A qualitative study. Int J Child Health Nutr 2014; 3: 27-40. http://dx.doi.org/10.6000/1929-4247.2014.03.01.4

Received on 22-07-2015

Accepted on 05-08-2015

Published on 11-12-2015

http://dx.doi.org/10.6000/1929-4247.2015.04.04.1

(c) 2015 Lindsay et al.; Licensee Lifescience Global.

This is an open access article licensed under the terms of the Creative Commons Attribution Non-Commercial License (http://creativecommons.org/licenses/by-nc/3.0/) which permits unrestricted, non-commercial use, distribution and reproduction in any medium, provided the work is properly cited. 